\title{
Transitory procaine-induced Parkinsonism
}

\author{
F. GJERRIS
}

\author{
From the Department of Neurology, Kommunehospitalet, Copenhagen K, Denmark
}

SUMmaRY A case of prolonged, though reversible procaine-induced Parkinsonism treated with L-dopa and trihexyphenidyl (Artane-Sustets) is reported. A pathophysiological explanation is discussed on the basis of recent theories concerning the transmitter systems of the basal ganglia.

The fully developed Parkinsonian syndrome is most frequently seen in paralysis agitans and after encephalitis. The course is invariably progressive (Selby, 1968).

Among the side-effects of psychotropic drugs, which have now been applied in the clinic for two decades, are transitory, so-called extrapyramidal reactions. Faurbye, Rasch, Petersen, Brandborg, and Pakkenberg (1964) have presented a survey with definitions of the commonest of these symptoms.

Parkinsonism, dystonic crises, and dyskinesia are most often elicited by psychotropic drugs of the phenothiazine group-chlorpromazine, methotrimeprazine and promazine-haloperidol, reserpine, and perphenazine. Usually the symptoms subside when the drug is discontinued or the dosage reduced, or they are relieved by anti-Parkinsonism-drugs.

In this paper, a case of Parkinsonism of sudden onset after injection of procaine-hydrocortisate is reported because of its lengthy course, with remission only after treatment with L-dopa and long-acting trihexyphenidyl (Artane-Sustets).

\section{CASE REPORT}

(Record no. 1143/68-69, KH Department of Neurology.) A 47 year old married woman was admitted with a diagnosis of paralysis agitans of sudden onset. There were no cases of neuropsychiatric disorders in the family. In 1963 the patient had been admitted to hospital because of a haemorrhagic disorder of the colon. There had been repeated short episodes of rheumatism of the neck, for which on two occasions she had been given intramuscular injections of procaine. After one of these injections she had experienced malaise of short duration and nausea. For about one and a half years she had been mentally strained and overworked, and during that period of time had regularly taken chlordiazepoxide $30-40 \mathrm{mg}$ daily and at times also meprobamate $400 \mathrm{mg}$ and/or pentobarbitone $100 \mathrm{mg}$ at night, but no other drugs.

Apart from mental strains she had been perfectly well until the present illness began on 31 July 1968. On that day she experienced a violent pain in the neck, for which $\overrightarrow{0}$ she was given on 1 August, an intramuscular injection in the shoulder of $2 \mathrm{ml} .2 \%$ procaine with adrenaline and $\vec{\omega}$ $75 \mathrm{mg}$ hydrocortisate. Thereafter she felt well for a couple of hours, but the pain in her neck and shoulder recurred, $\Xi$ and on 2 August she was given another similar injection. ?

Fifteen to thirty minutes after the last injection, when $\underset{\perp}{\oplus}$ driving by car to her summer cottage, she developed malaise and nausea, and one and a half hours after the iv injection she experienced a sensation of swelling and incoordination of the tongue, which she was unable keep still. At the same time there was a sensation $\rightarrow$

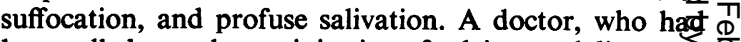
been called, gave her an injection of calcium and diazepam and her symptoms subsided until 3 August, when the lingual symptoms recurred. Another injection of diazepair brought relief. In the week from 5 to 9 August ske complained of 'jitters', restlessness, and difficulty in remaining seated. She continued taking $10 \mathrm{mg}$ chlor- diazepoxide thrice daily, and $\mathbf{4 0 0} \mathrm{mg}$ meprobamate and $100 \mathrm{mg}$ pentobarbitone at night as usual. From 10 August it gradually became difficult for her to move her arms and legs because of stiffness, increasing fatigue, and difficulty in turning over in bed and in feeding herself. Moreover, $\frac{O}{D}$ there was increasing stiffness of the facial muscles with immobile face and drooling. The treatment was changed to chlorzoxazone four tablets a day for three to four days followed by chlorpromazine $25 \mathrm{mg}$ thrice daily for an additional two days, without relief of the symptoms. From 18 August until admission on 20 August she received no medicine whatsoever.

On admission she was weeping and depressed. Neurological examination revealed a mask-like face, oligomimia, greasy skin and asymmetry of the face, severe rigidity of the trapezius muscles, pronounced hypertonicity with plastic rigidity in both arms and a suggestion of cogwheel rigidity on the right side, moderate hypokinesia, mild impairment of quick alternating movements of the hands, and exaggerated, equal deep reflexes. There was marked plastic rigidity of the left leg and cogwheel rigidity of the right. The gait was short-stepping with $\mathrm{N}$ failure to swing her arms; her handwriting was neat; micrography was not present, and there was no tremor. The severe Parkinsonian symptoms still persisted eight 
days after admission, during which time she received no medicine whatsoever, and she was given $\mathrm{L}$-dopa, $1 \mathrm{~g}$ three times a day. Her condition did not change during the next two days and $5 \mathrm{mg}$ Artane-Sustets was added in the mornings. Over the next eight days there was considerable improvement, with decreasing hypokinesia, including the face. Gait and running became normal with swinging of both arms. L-dopa was then discontinued as was ArtaneSustets four days later. During the next three days pronounced Parkinsonian features recurred, and $5 \mathrm{mg}$ Artane-Sustets in the mornings was re-instituted. Her condition again improved and she was discharged.

Continued outpatient medication with Artane-Sustets $10 \mathrm{mg}$ daily was recommended, and she was seen at regular intervals. On examination at the beginning of November 1968 she presented no Parkinsonian features whatsoever, and the neurological examination was perfectly normal. On this occasion the patient stated that she had been taking chlordiazepoxide and pentobarbitone as usual. On 18 November Artane-Sustets was reduced to $5 \mathrm{mg}$ daily and on 25 November the drug was discontinued. When last seen (May 1970) there was no evidence of recurrence.

\section{DISCUSSION}

The patient consecutively presented two clinical pictures, one of dyskinesia, particularly oral dyskinesia as the predominant feature, and one of a florid Parkinsonism.

Ayd (1961) stated that drug-induced Parkinsonism occurs twice as often in women as in men, while dyskinesias are twice as frequent in men as in women. In $90 \%$ of the cases the dyskinetic symptoms developed within the first four and a half days, while the Parkinsonian syndrome appeared only after two or three weeks. Some of the patients first developed dyskinetic symptoms and, in a later stage of the treatment, a Parkinsonian syndrome very similar to that of the present patient.

Hydrocortisate, according to the literature, is unlikely to produce a similar clinical picture, even when given intrathecally (Mack, 1964).

Adrenaline causes tremor in normal subjects (Marshall, 1968), whereas adrenaline given to patients with Parkinsonism, either intravenously in dosages of $20 \mu \mathrm{g}$, or intramuscularly in dosages of $1 \mathrm{mg}$, increases the amplitude, though not the frequency of the trembling (Constas, 1962). The present patient, who was given $10 \mu \mathrm{g}$ intramuscularly, developed no tremors. Neither have examples of adrenaline producing other Parkinsonian symptoms been reported.

The action of procaine in the brain is either stimulatory, causing restlessness and trembling, even convulsions, and/or depressor, leading to respiratory arrest and death (Møller, 1958). The same reactions are seen after intraventricular and intracisternal injections (Haranath, Begum, and Sitaramayya, 1965). Frank and Sanders (1963), however, found that procaine on brain slices had only a depressor effect on the synapses and ascribed its stimulatory action to a selective depression of inhibitory neurones. Parkinsonism after injection of procaine has not been reported.

Several neurohumoral transmitter systems are present in the basal ganglia of the brain. Of these the dopaminergic and the cholinergic systems are believed to exert an antagonistic effect (cf. surveys by Hornykiewics, 1966; Duvoisin, 1967; Curzon, 1967; Klawans, 1968). The mechanisms responsible for the drug-induced transitory extrapyramidal symptoms are obscure; however, in cases of Parkinsonism they may be ascribed to a blocking effect on the synapses of the dopaminergic system (Klawans, 1968). In our patient, procaine may first have exerted an irritative effect on the extrapyramidal system resulting in increased dopamine action and in dyskinesia (cf. Cotzias, Papavasiliou, and Gellene (1969) who observed dyskinetic symptoms during L-dopa therapy). She did not respond to L-dopa treatment of short duration, which is in accord with McGeer, Boulding, Gibson, and Foulkes's findings (1961) of inefficacy of L-dopa on druginduced extrapyramidal symptoms. Cholinergic mechanisms must also have been involved, since the symptoms improved promptly on anticholinergic drugs and even disappeared completely during sustained treatment.

Chlordiazepoxide given alone, even in large amounts, elicited but few and very mild extrapyramidal symptoms (Gjerris, 1966); however, when given in combination with other psychotropic drugs, neurological deficits have been observed (Kane, and Taylor, 1963; Kane and McCurdy, 1964). In the present case the cerebral affection may be explained by interaction between chlordiazepoxide, meprobamate, barbiturate, and procaine in a predisposed subject.

A large number of drugs have been accused of inducing Parkinsonism. Schwab and England (1968), however, warn against postulating a causal relationship, stressing that a great number of cases may represent mere coincidence or an aggravation of a subclinical Parkinsonism, which might otherwise have remained dormant for years. However Parkinsonian symptoms elicited by psychotropic drugs, and eventually followed by true Parkinsonism, has not been reported in the literature.

\section{REFERENCES}

Ayd, F. J., jr. (1961). A survey of drug-induced extrapyramidal reactions. J. Amer. med. Ass., 175, 1054-106 
Constas, C. (1962). The effects of adrenaline, noradrenaline and isoprenaline on Parkinsonian tremor. J. Neurol. Neurosurg. Psychiat., 25, 116-121.

Cotzias, G. C., Papavasiliou, P. S., and Gellene, R. (1969). Modification of Parkinsonism: chronic treatment with L-dopa. New Engl. J. Med., 280, 337-345.

Curzon, G. (1967). The biochemistry of dyskinesias. Int. Rev. Neurobiol., 10, 323-370.

Duvoisin, R. C. (1967). Cholinergic-anticholinergic antagonism in Parkinsonism. Arch. Neurol. (Chic.), 17, 124-136.

Faurbye, A., Rasch, P.-J., Petersen, P. B., Brandborg, G., and Pakkenberg, H. (1964). Neurological symptoms in pharmacotherapy of psychoses. Acta psychiat. scand., 40, 10-27.

Frank, G. B., and Sanders, H. D. (1963). A proposed common mechanism of action for general and local anaesthetics in the central nervous system. Brit. J. Pharmacol., 21, 1-9.

Gjerris, F. (1966). Poisoning with chlordiazepoxide (Librium). Dan. med. Bull., 13, 170-172.

Haranath, P. S. R. K., Begum, N. A., and Sitaramayya, G. V. (1965). The effects of procaine injected into the cerebral ventricles of conscious and anaesthetized dogs. Brit. J. Pharmacol., 24, 339-347.

Hornykiewics, O. (1966). Dopamine (3-hydroxytyramine) and brain function. Pharmacol. Rev., 18, 925-964.

Kane, F. J., and Taylor, T. W. (1963). A toxic reaction to combined Elavil-Librium therapy. Amer. J. Psychiat., 119, 1179-1180.

Kane, F. J., and McCurdy, R. L. (1964). An unusual reaction to combined Librium-barbiturate therapy. Amer. $J$. Psychiat., 120, 816-17.

Klawans, H. L., jr. (1968). The pharmacology of Parkinsonism. Dis. nerv. Syst., 29, 805-816.

Mack, E. W. (1964). Intrathecal steroid administration. Rocky Mtn med. J., 61, 33-34.

Marshall, J. (1968). Tremor, in Handbook of Clinical Neurology, vol. 6, pp. 809-25. Edited by P. J. Vinken and G. W. Bruyn. North-Holland Publishing Co.: Amsterdam, N.Y.

McGeer, P. L., Boulding, J. E., Gibson, W. C., and Foulkes, R. G. (1961). Drug-induced extrapyramidal reactions. Treatment with diphenhydramine hydrochloride and dihydroxyphenylalanine. J. Amer. med. Ass., 177, 665-670.

Møller, K. O. (1958). Farmakologi. 5th ed. Nyt Nordisk Forlag: København.

Schwab, R. S., and England, A. C., jr. (1968). Parkinson syndromes due to various specific causes, in Handbook of Clinical Neurology, vol. 6, pp. 227-247. Edited by P. J. Vinken and B. W. Bruyn. North-Holland Publishing Co. Amsterdam, N.Y.

Selby, G. (1968). Parkinson's disease, in Handbook of Clinical Neurology, vol. 6, pp. 173-211. Edited by P. J. Vinken and G. W. Bruyn. North-Holland Publishing Co.: Amsterdam, N.Y. 